\title{
$\mathrm{u}$-웰니스를 위한 $\mathrm{u}$-헬스케어 시스템의 설계와 구현 \\ 서현수 ${ }^{1}$, 류대현 $^{1^{*}}$, 최태완 ${ }^{2}$ \\ ${ }^{1}$ 한세대학교 IT학부, ${ }^{2}$ 경남과학기술대학교 메카트로닉스공학과
}

\section{Design and Implementation of u-Healthcare System for u-Wellness}

\author{
Hyunsoo Seo ${ }^{1}$, Dae-Hyun $\mathrm{Ryu}^{1^{*}}$ and Taewan $\mathrm{Choi}^{2}$ \\ ${ }^{1}$ Divion of IT, Hansei University \\ ${ }^{2}$ Dept. of Mechatronics Eng., Gyeongnam National University of Science and Technology
}

\begin{abstract}
요 약 본 u-웰니스는 병원 등 의료서비스 공급자 측과 개인에게 광범위하게 적용하는 개념으로, 공급 측의 u-피트 니스, 화상 건강 상담 서비스 등과 함께 개인 측면의 스트레스 관리, 비만 관리, 운동량 체크 등을 포함하는 개념이 다. 본 논문에서는 개인을 식별하는 인증장치로 사용자의 스마트폰을 사용하고 이 장치를 통해 체지방 분석, 건강관 리 전문가의 처방기록을 받은 기록을 바탕으로 운동기구들과 $\mathrm{Wi}-\mathrm{Fi}$ 통신을 통하여 운동량을 측정 및 관리하는 $\mathrm{u}$-헬 스케어 시스템을 설계하고 구현 하였다. 본 시스템은 건강관리 전문가의 처방을 통해 사용자의 최적화된 운동량을 처방 받아 효율적인 운동을 할 수 있도록 해준다. 또한 본 시스템은 체지방 측정기계와 전문가의 측정 결과를 수치 화 하고 운동기구들의 이용 횟수 등을 데이터베이스로 구축하고 자동 스케줄 관리를 해준다.
\end{abstract}

\begin{abstract}
Wellness is widely applicable to individuals and medical service providers such as hospitals and it includes u-fitness and video health counselling services at the side of the provider and stress management, obesity management, and the amount of exercise at the side of the individual. In this paper, we design and implement a smart health care system which uses the authentication device to identify an individual and the user's smart phone. Our system records and manages the amount of exercise on the basis of the prescription of health care professionals through the exercise equipment and Wi-Fi communication. Therefore, our system helps user do optimized amount of exercise through the health care professional's prescription. And our system quantifies the results of the measurement of body fat measuring machines and experts to build the database and automatically schedule.
\end{abstract}

Key Words : U-wellness, U-healthcare, Smartphone, Ubiquitous, USN

\section{1. 서론}

최근 국민소득 수준향상과 더불어 개인의 행복추구에 대한 요구가 증대되고 있으며, 정보통신 기술을 활용하여 효율적이고 편리하게 건강을 관리하는 기술에 대한 요구 가 증가하고 있다. 또한 고령화 사회의 도래에 따른 환경, 생활, 건강 등 다양한 요소가 유기적인 융합을 통해 USN 기반의 개인 맞춤형 운동 관리 및 예방의 사회적 요구에
따른 u-헬스(u-Health) 관련 신규서비스에 대한 수요가 증 가하고 있다.

$\mathrm{u}$-헬스는 정보 통신과 보건 의료를 연결하여 언제 어 디서나 예방, 진단, 치료, 사후 관리의 보건 의료 서비스 를 제공하는 개념이다. 이 헬스(e-Health)가 시민, 환자, 보건 의료 기관, IT 기업, 솔루션 업체 사이에서 전자적으 로 보건 의료 정보를 교환하는 것이라면, $\mathrm{u}$-헬스는 이들 을 포괄하는 물리적 공간과 네트워크로 연결된 첨단 보

본 논문은 경남과학기술대학교 2011년도 기성회 연구비 지원에 의해 연구되었음.

"Corresponding Author: Dae-Hyun Ryu

Tel: +82-31-450-5228 email: dhryu@hansei.ac.kr

접수일 12 년 10 월 22 일 수정일 12 년 11 월 06 일 게재확정일 12 년 11 월 08 일 
건 의료 기술의 전자적 공간을 연결하여 보건 의료 대상 자의 삶과 진료가 중심이 되도록 하는 것을 뜻한다.

보건 의료 기술의 급격한 발전과 정보의 디지털화, 통 신의 광대역화, 유무선 통신망을 통한 대용량의 정보를 빠르게 전송할 수 있게 되었으며, 멀티미디어 처리 및 저 장 기술의 발전, RFID를 비롯한 각종 유비쿼터스 환경의 등장으로 $\mathrm{u}$-헬스의 현실화가 빠르게 진행되고 있다.

u-웰니스(u-Wellness)란 웰빙(Wellbeing)과 휘트니스 (Fitness)를 결합한 용어로 원격 건강 관리 시스템을 의미 하는데 u-헬스의 한 분야로 IT를 이용해 더욱 효율적이고 편리하게 건강을 관리하는 시스템이라 할 수 있다. 운동 을 하면서 실시간으로 자신의 운동량과 강도 정보를 체 크할 수 있으며, 이 정보를 바탕으로 인터넷을 이용해 운 동 패턴, 생활 습관, 영양 상태 같은 맞춤형 건강 관리와 컨설팅도 받을 수 있다. 즉, 건강관리와 IT가 융합되어 제공되는 서비스라 말할 수 있다. 이러한 $\mathrm{u}$-웰니스는 스 마트폰이 활성화와 더불어 모바일 기반의 웰니스 앱 (Wellness App.)이 배포되면서 사용자들이 서서히 그 개 념을 정립하고 있다.

본 논문에서는 개인을 식별하는 인증장치로 사용자의 스마트폰을 사용하고 이 장치를 통해 체지방 분석, 건강관 리 전문가의 처방기록을 받은 기록을 바탕으로 운동기구 들과 Wi-Fi 통신을 통하여 운동량을 측정 및 관리하는 u헬스케어 시스템을 설계하고 구현을 하였다. 전체 건강관 리 시스템의 관리를 위한 관리 서버(Management Server) 와 운동기구에 설치될 측정 장치로 $\mathrm{WinCE}$ 기반의 장치 노드(DeviceNode)를 사용 하였으며, 안드로이드 스마트 폰을 이용하여 사용자 인증장치를 구현하였다.

본 논문의 2 장에서는 관련연구를, 3 장에서는 시스템의 설계와 구현에 대해 기술하고 4 장에서 결론을 맺는다.

\section{2. 관련 연구}

$\mathrm{u}$-헬스 관련 사업은 $\mathrm{u}$-병원(u-Hospital), 홈-모바일 헬스 케어, 웰니스 등 세 가지로 구분되고 있다[1]. 이 중 u-웰 니스는 병원 등 의료서비스 공급자 측과 개인에게 광범위 하게 적용하는 개념으로, 공급 측의 $\mathrm{u}$-휘트니스(u-Fitness), 화상 건강 상담 서비스 등과 함께 개인 측면의 모바일 스 트레스 관리, 비만 관리, 운동량 체크 등을 포함한다.

지식경제부도 'u-헬스 신산업 창출전략' 발표를 통해 $\mathrm{u}$-헬스 서비스를 치료 중심의 $\mathrm{u}$-메디컬, 노령자 요양 중 심의 $\mathrm{u}$-실버, 그리고 일반인 건강관리 중심의 $\mathrm{u}$-웰니스로 구분했다[2]. 국내에서도 지금까지 u-헬스 디바이스나 솔 루션들에 대한 다양한 연구가 진행되어 왔으며, 이를 적
용한 테스트베드 구성과 u-헬스의 부분적 시범서비스를 실시하여 왔다. 이제는 한 단계 업그레이드를 위하여 스 마트 네트워크에 기반한 실시간 및 통합 u-헬스 시범서비 스로 발전되어야 할 단계가 되었다[3-5].

$\mathrm{u}$-헬스에서 USN 기반의 운동 관리 시스템은 개개인의 특성화된 최적의 맞춤형 운동 관리를 위해 개발된 시스 템으로 운동량과 생체데이터를 수집하며, Zigbee 또는 $\mathrm{WiFi}$ 무선 방식으로 데이터를 실시간으로 전송하고 이를 관리 서버에서 분석가공하여 저장하기 때문에 언제 어디 서나 인터넷 환경 또는 스마트폰을 포함한 무선 인터넷 에서 열람할 수 있으며, 운동처방에 객관적인 피드백 자 료를 제공할 수 있다.

뿐만 아니라 운동처방 및 이에 대한 효율적인 관리를 필요로 하는 여러 현장에서 과학적 운동 프로그램의 혜 택을 제공할 수 있다. 예를 들어 재활치료센터나 휘트니 스 센터 등에서 운동을 통한 재활치료나 건강관리 과정 에서 겪는 불편함이나 무리한 운동 치료로 인해서 발생 할 수 있는 위험한 상황을 미연에 방지할 수 있다. 또한 운동 관리 또는 재활 치료 인력 절감 효과를 볼 수 있을 뿐 아니라 관리 인력의 실수로 인해 발생 할 수 있는 위 험을 초기에 방지할 수 있다. 그리고 운동 요법 또는 재 활 치료에 대한 $\mathrm{DB}$ 가 구축되기 때문에 체계적인 관리의 효율성이 증대할 수 있다.

운동정보를 측정하고 관리해주는 u-웰니스 상품은 이 미 시중에 다양하게 출시돼있다. 대표적인 예가 나이키와 애플이 제휴해 내놓은 '나이키+아이팟 스포츠 키트'다. 2006년 7월 미국에서 첫 발매한 이 상품은 왼쪽 신발 바 닥에 센서를 장착해 사용자의 운동정보를 측정, 아이팟 디스플레이를 통해 확인할 수 있도록 고안됐다. 이뿐만 아니라 별도의 웹사이트에서 사용자가 자신의 주행 이력 을 분석하거나 다른 사람의 주행 이력과 비교 분석도 가 능하다.

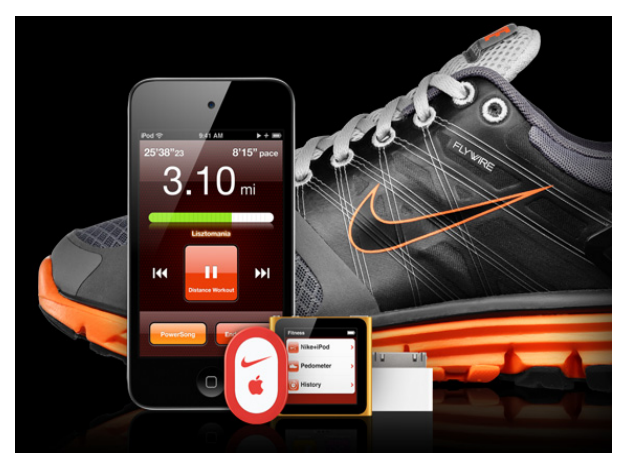

[그림 1] 나이키+아이팟 스포츠 키트

[Fig. 1] Nike + iPod Sport Kit 
비슷한 사례로는 아디다스의 건강 셔츠가 있다. 아디 다스는 심장의 박동수를 체크하는 기능을 가진 '건강 셔 츠'를 내놨다. 이 기록은 블루투스 등을 이용해 PC로 전 송할 수 있다.

운동정보 뿐만 아니라 스트레스 및 다이어트 등도 모 바일을 통해 관리할 수 있다. 모바일로 스트레스 지수·자 율신경 평형도 등을 측정해 음악치료·운동요법· 심리치료 전문가와의 문자-상담과, 스트레스를 풀 수 있는 게임·동 영상 콘텐츠 등이 모두 $\mathrm{u}$-웰니스 산업군으로 분류될 수 있다.

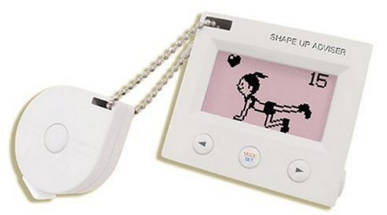

[그림 2] 세이프 업 어드바이저

[Fig. 2] Shape Up Adviser

일본 게임업체 남코 반다이사의 '세이프 업 어드바이 저'는 운동 트레이너와 다이어트 관리자의 역할을 해주 는 $\mathrm{u}$-웰니스 오락기기다. 작은 스크린이 장착된 소형의 이 기기는 칼로리를 계산하고 다이어트에 방해되는 유혹 들을 이길 수 있는 기능을 제공한다. 지나치게 높은 칼로 리를 섭취하면 경고메시지를 화면에 보여주는 식이다. 마 쓰시타사는 조명 및 침대 등 10 가지 가전을 통합 제어하 며 쾌적한 수면 환경을 제공하는 '쾌면 시스템’을 내놨다. 침대 밑에 있는 접촉 수면센서로 수면자의 동작이나 심 박신호를 계측, 분석해 가전기기 등을 제어하는 시스템이 다. 이를테면 꾸벅꾸벅 잠이 드는 상태를 감지하면 전등 이 꺼지고 음향기기의 음량이 서서히 줄어들게 되는 것 이다.

\section{3. 시스템 설계 및 구현}

\section{1 시스템 구조}

본 논문에서 설계한 $\mathrm{u}$-헬스케어 시스템의 전체 구성도 를 그림 3에 나타내었다. 구현상 크게 사용자 관리 서버, 사용자 인증 노드, 운동 및 신체 상태 측정 장치로 나뉜다.

사용자 관리 서버는 건강 관리 전문가가 $1: \mathrm{n}$ 의 관리 를 효율적으로 하기 위한 웹서비스를 지원하는 서비스이 다. 사용자는 이 웹서비스를 통하여 최초 자신의 정보를 서버에 등록한 후 이후 지속적으로 자신의 건강 상태를
업데이트 하여 관리를 받는다.

사용자 인증노드는 자신의 건강 상태 및 운동 결과를 업데이트할 때 자신을 인증하고, 언제 어디서나 사용자가 현재 상태를 파악 할 수 있도록 구현한다. 일반적으로 사 용자가 항상 소지하는 모바일 장치를 이용하는데 본 논 문에서는 안드로이드 기반의 스마트폰을 이용한다.

운동을 위한 장치로는 일반적으로 널리 알려진 트레드 밀(Treadmill), 벤치프레스(Bench Press), 자전거(Bike)를 사용하는데 구현 편리상 $\mathrm{WinCE}$ 기반의 임베디드 장치를 이용하여 각각의 에뮬레이터를 구현한다.

\section{2 사용자 시나리오}

$\mathrm{u}$-웰니스 건강관리 서비스는 다음과 같은 동작 순으로 진행 된다.

1. 회원 등록 (Web)

2. 체지방 및 운동 부하검사

3. 건강관리 전문가의 운동 처방

4. 1 일분 운동 준비

5. 사용자 인증

6. 운동(Bike, Treadmill, Bench Press)

7. 운동 결과 저장

8. 분석 및 피드백

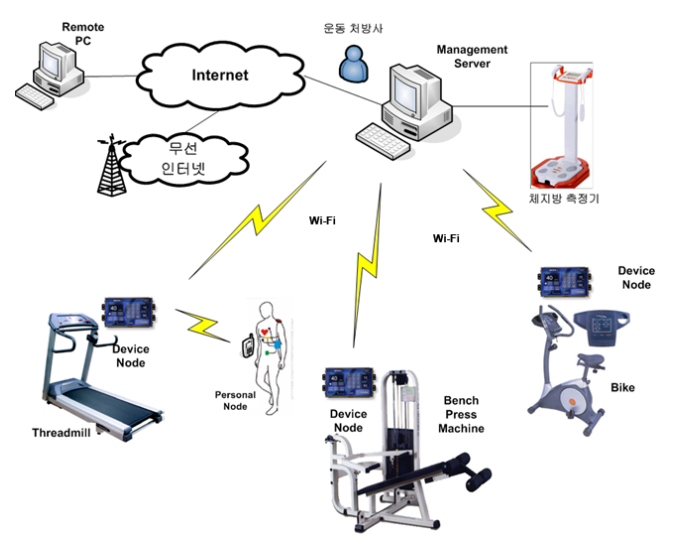

[그림 3] u-헬스케어 시스템 구성도

[Fig. 3] Configuration of u-Health System

그림 4에 위 동작 순서를 나타내었으며 구체적인 서비 스 절차는 다음과 같다.

1) 사용자는 먼저 관리시스템에 계정을 만든 후 체지방 측정 및 운동 부하검사 등을 통해 자신의 건강 상태를 확인한다.

2) 건강관리 전문가와의 상담을 통해 운동의 종류와 일일 단위의 운동 처방을 내리고 이 내용을 관리시스템에 
입력한다.

3) 건강관리 전문가의 처방전과 체지방 측정 결과는 $\mathrm{DB}$ 에 저장되고 이것은 웹 또는 스마트폰을 통해 사용자 가 정보를 열람 할 수 있다.

4) 사용자는 일일 처방 내용과 현재 사용 가능한 운동 기 구를 확인한 후 사용하고 사용자가 운동을 하는 동안 관리서버와 와 각 운동기기는 $\mathrm{WiFi}$ 를 통해 운동중인 사용자의 상태를 실시간으로 체크 하게 된다.

$5)$ 모든 데이터는 건강관리 전문가 또는 의사에 의해 분 석되고 웹이나 스마트폰을 통해 사용자에게 피드백 된다.

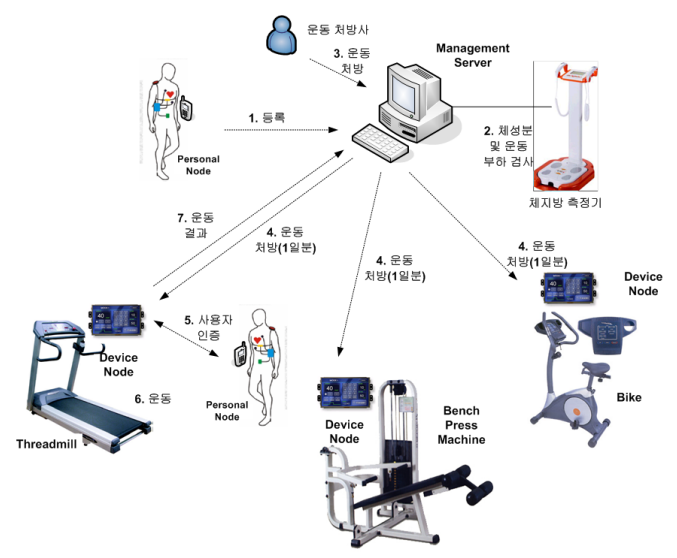

[그림 4] 사용자 시나리오

[Fig. 4] User Scenarios

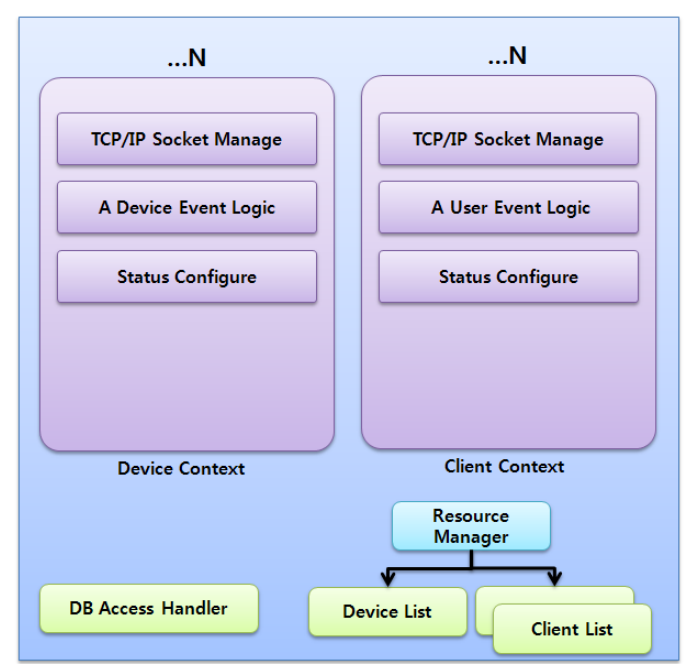

[그림 5] 서버 소프트웨어 구성도

[Fig. 5] Configuration of Server Software
서버는 그림 5와 같이 크게 Device Context, Client Context와 DB Access Handler, Resource Manager 로 구 성 되어 있다. 두 Context는 MFC Socket Class를 상속 받 아 Selected 방식의 $\mathrm{TCP} / \mathrm{IP}$ 동작을 한다. 각 Context는 각 각의 1 개의 Device와 1 명의 User와 $1: 1$ 대응 하도록 되어 있고, 이 Context들은 Resource Manager를 통해 관리된 다. 그리고 Device와 User간의 통신에서 Event Logic을 처리 하는데 전역적인 $\mathrm{DB}$ Access Handler를 사용한다.

\section{3 시스템 구현}

본 논문에서는 7 인치 $\mathrm{LCD}$ 를 갖는 $\mathrm{WinCE}$ 임베디드 시스템을 이용하여 세가지 운동기구와 체지방 측정기의 에뮬레이터를 구현하고 이를 이용하여 $\mathrm{u}$-헬스케어 시스 템을 구축하였다. 본 시스템의 데모를 위해 그림 5 과 같 이 구성하였으며 개발환경을 다음과 같다.

- Server

- WindowXP

- DB : My SQL

- Web : Apache Server \& PHP

- DB Client Win32 API

- Device Node

- WinCE (IEC266)

- MFC base

- 스마트폰

- Android OS

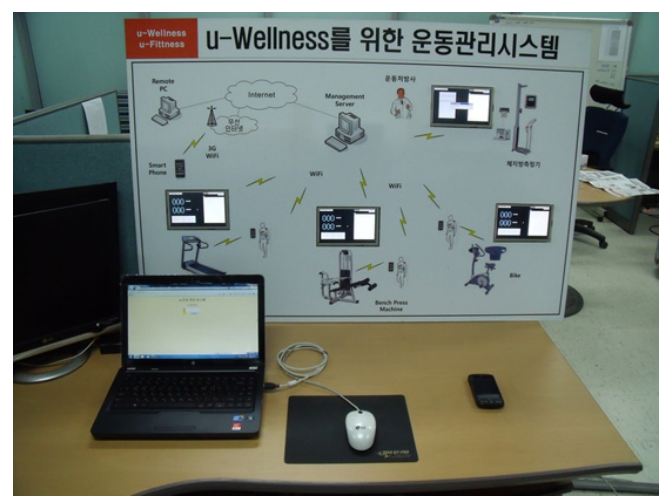

[그림 6] 데모용 시스템

[Fig. 6] Demonstration System

유비쿼터스 기반의 서비스를 위해 TCP/IP기반의 네트 워크 통신을 한다. 이때 각각 네트워킹을 하는 주체를 노 드(node)라고 하며, 한대의 서버와 다수의 클라이언트를 연동 할 수 있는 구조를 갖는다. 이 시스템의 사용자 인 
증 노드(스마트폰)과 관리서버 간에 이 방식이 사용되는 데 그림 7에 그 구조를 나타내었다.

클라이언트의 요청(request)과 서버의 응답(response) 으로 이루어지는 통신에서는 표 1 과 같은 메시지를 처리 한다. 표 1 에 나타난 관리서버의 요청들의 대부분은 정보 저장 및 전달이다. 이것들을 효율적으로 처리하기 위해 $\mathrm{DB}$ 를 사용할 필요가 있는데 본 논문에서는 $\mathrm{my-SQL}$ 을 사용 하였다. 그림 8 에 이 $\mathrm{DB}$ 를 사용하여 구현된 데이터 다이어그램을 나타내었다.

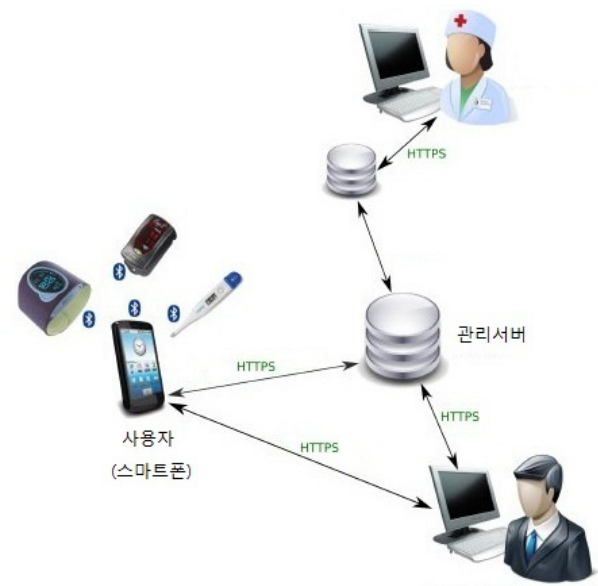

[그림 7] 관리서버 와 인증 노드의 관계

[Fig. 7] Relationship between Management Server and Authentication Nodes

[표 1] 주요 통신 메시지

[Table 1] Main Communication Messages

\begin{tabular}{|c|c|c|}
\hline 카테고리 & 주요기능 & 요청방향 \\
\hline _LOGIN_ & ID/PW login & $\begin{array}{c}\text { SmartPhone -> } \\
\text { Server }\end{array}$ \\
\hline _AUTH_ & Devices auth & Device -> Server \\
\hline _DEVICE_READ & $\begin{array}{c}\text { Ready for } \\
\text { play }\end{array}$ & $\begin{array}{c}\text { Device -> } \\
\text { SmartPhone }\end{array}$ \\
\hline Y_ & Start play & User -> Server \\
\hline _JOIN_ & PlayResult & User -> Server \\
\hline _REPORT_
\end{tabular}

운동장비의 시뮬레이션을 위한 임베이디드 $\mathrm{WinCE}$ 장치는 터치스크린을 통해 사용자의 입력을 받는다. 이때 스크린 상에 보여지는 UI를 트레드밀이나 자전거 의 계기판과 유사하게 구성하여 시뮬레이션이 가능 하 도록 하였다(그림 9). 이 장치는 실제 운동 장비를 사 용하여 구현한 것처럼, 각 운동의 실효 효과를 나타내 기 위한 반복 횟수를 운동 지표로 활용 한다.

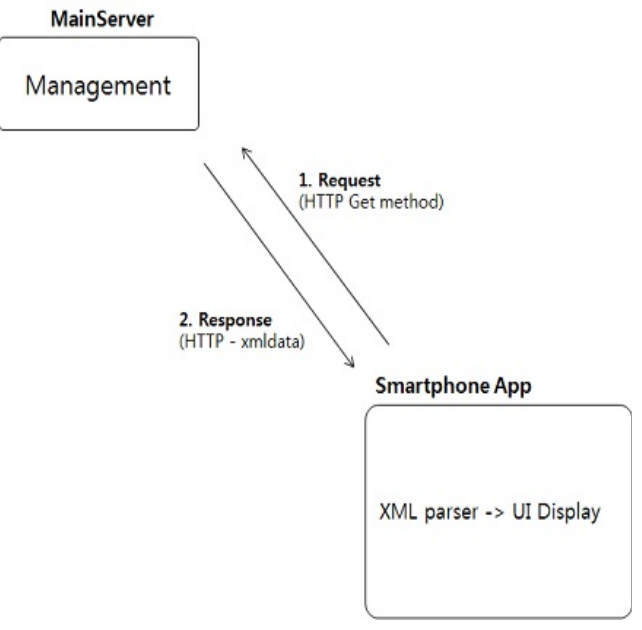

[그림 8] 관리서버 데이타 다이어그램

[Fig. 8] Data Diagram of Management Server

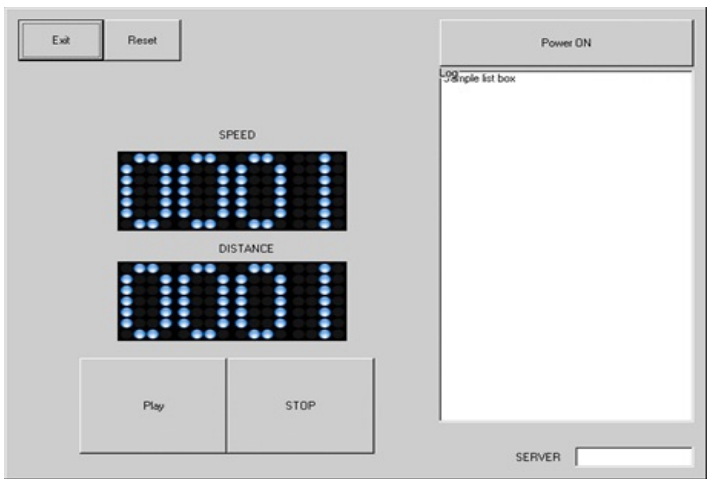

[그림 9] 운동장비 시뮬레이션 화면

[Fig. 9] Simulation Screen of Exercise Equipment

\section{4. 결 론}

$\mathrm{u}$-웰니스 서비스는 건강관리와 IT가 융합되어 제공되 는 서비스로 스마트폰의 활성화와 함께 발전하고 있다.

본 논문에서는 개인을 식별하는 인증장치로 사용자의 스마트폰을 사용하고 이 장치를 통해 체지방 분석, 건강 관리 전문가의 처방기록을 받고 받은 기록을 바탕으로 운동기구들과 $\mathrm{Wi}-\mathrm{Fi}$ 통신을 통하여 운동량을 측정 및 관 리하는 $\mathrm{u}$-헬스케어 시스템을 설계하고 구현 하였다. 본 시스템은 전문가의 처방기록을 받은 기록을 바탕으로 운 동기구들과 네트워크 통신을 통하여 운동량을 측정 및 관리를 통해 관리를 효율적으로 하여 운동 효과를 높히 도록 해준다.

향후 소셜네트워크 서비스(페이스북, 트위터 등)와 통 
합을 통해 본 서비스를 이용하는 사용자들의 커뮤니티를 만들어 서비스의 집중도를 높이고, 유관기관의 OpenAPI (서울시의 공원 찾기, 약국 찾기)를 통해 관련된 정보를 쉽게 전달 할 수도 있을 것이다.

\section{References}

[1] Jeein Kwon, "IT Enterprise Expansion Trend of u-Health Industry", Information Communication policy, Samsung Economic Research Institute(SERI), pp. 52-56, Nov. 2007.

[2] Ministry of Knowledge Economy, "New Industrial Creation Strategy of u-Health", Division of Growth Power Policy, May 2010.

[3] S.M. Park, "Technical Trend of Sensor Network Node Platform \& OS", Trend Analysis of Electronics and Telecommunications, ETRI, vol. 21, no. 1, p. 15, Feb. 2006.

[4] M.H. Chae, "Analysis System for Dumbbell Curl Exercise based on Wireless Sensor Networks", Journal of KIISE : Computing Practices and Letters, vol. 18, no. 1, Jan. 2012.

[5] Y. Wang, L. Li, B. Wang L. Wang, "A Body Sensor Network Platform for In-home Health Monitoring Application", 4th international conference on ubiquitous information technologies \& applications (ICUT 2009), pp. 1-5, 2009.

[6] PHP Developer Website of introduction : http://www.php.net/manual/en/introduction.php

[7] PHP Developer Website : http://www.php.net/

[8] Android Developer Website : http://developer.android. com/guide/topics/fundamentals/services.html

\section{서 현 수(Hyun-Soo Seo)}

[준회원]

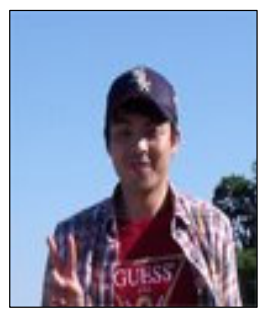

- 2010년 2월 : 한세대학교 IT학부 졸업

- 2010년 3월 현재 : 한세대학 교 대학원 IT융합학과 재학중(석 사과정)

<관심분야>

u-Healthcare, u-Wellness, 임베디드시스템

\section{류 대 현(Dae-Hyun Ryu)}

[정회원]

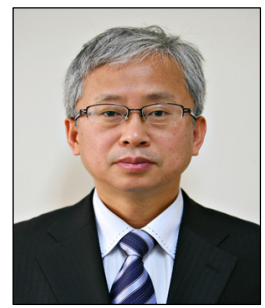

- 1983년 2월 : 부산대학교 대학원 전자공학과 (공학석사)

- 1997년 2월 : 부산대학교 대학원 전자공학과 (공학박사)

- 1987년 3월 1998년 2월 : 한 국전자통신연구원 선임연구원

- 1998년 3월 현재 : 한세대학 교 IT학부 교수

<관심분야>

정보통신, 정보보호, 영상처리, IoT, u-Healthcare

\section{최 태 완(Taewan Choi)}

[정회원]

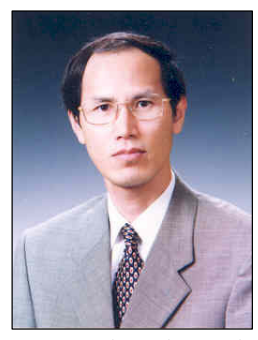

- 1983년 2월 : 부산대학교 대학원 전자공학과 (공학석사)

- 1996년 2월 : 부산대학교 대학원 전자공학과 (공학박사)

- 1984년 12월 1991년 2월 : (주)LG전자 디지털어플라이언스 연구소 선임연구원

- 1997년 3월 현재 : 경남과학기술대학교 메카트로닉 스공학과 교수

<관심분야>

정보통신, 영상처리, Compute Vision, u-Healthcare 